\title{
Strain rate dependence of mode II delamination resistance in through thickness reinforced laminated composites
}

\author{
Mehdi Yasaee $^{\mathrm{a}^{*}}$, Galal Mohamed ${ }^{\mathrm{b}}$, Antonio Pellegrino ${ }^{\mathrm{c}}$, Nik Petrinic ${ }^{\mathrm{c}}$, Stephen R. \\ Hallett $^{\mathrm{b}}$ \\ a School of Aerospace, Transport and Manufacturing, Building 83, University of Cranfield, Cranfield, \\ MK430AL,UK*m.yasaee@cranfield.ac.uk \\ b Advanced Composites Centre for Innovation and Science (ACCIS), University of Bristol, Queen's \\ Building, University Walk, Bristol, BS8 ITR, UK \\ c Department of Engineering Science, Engineering and Technology Building, \\ Parks Road, Oxford OXI 3PJ
}

\section{Abstract}

A thorough experimental procedure is presented in which the mode II delamination resistance of a laminated fibre reinforced plastic (FRP) composite with and without Zpins is characterised when subjected to increasing strain rates. Standard three-point End Notched Flexure (3ENF) specimens were subjected to increasing displacement loading rates from quasi-static $(\sim 0 \mathrm{~m} / \mathrm{s})$ to high velocity impact $(5 \mathrm{~m} / \mathrm{s})$ using a range of test equipment including drop weight impact tower and a Modified Hopkinson Bar apparatus for dynamic three-point bending tests.

The procedure outlined uses compliance based approach to calculate the fracture toughness which was shown to produce acceptable values of $\mathrm{G}_{\text {IIC }}$ for all loading rates. Using detailed high resolution imaging relationships between delamination velocities, apparent fracture toughness, longitudinal and shear strain rates were measured and compared. Confirming behaviours observed in literature, the thermosetting brittle epoxy composite showed minor increase in $\mathrm{G}_{\mathrm{IIC}}$ with increase in strain rate. However, the Z-pinned specimens showed a significant increase in the apparent $\mathrm{G}_{\text {IIC }}$ with loading rate. This highlights the need to consider the strain rate dependency of the Zpinned laminates when designing Z-pinned structures undergoing impact.

\section{Keywords}

Composites; delamination; impact; fracture toughness; Z-pin 


\section{Introduction}

Environmental, financial and performance requirements in global transport and energy industries necessitates ever more fuel efficient and high performance engineering structures and components. One method to tackle all of these requirements is to reduce the weight of components whilst maintain the same structural performance. For this reason laminated composite materials have seen an increased usage across all these sectors. These materials provide exceptional specific stiffness relative to their metal counter parts, amongst many other benefits such as corrosive resistance and fatigue performance.

However, the use of laminated composites does possess some drawbacks. The anisotropy of the material and manufacturing challenges results in a costly product development cycle. Furthermore, laminated composites do not possess any through thickness reinforcements, hence a major failure mechanisms of these materials is debonding or delamination of individual ply layers. Although, composite components are by design, capable of carrying in-service stresses, localised out of plane loading in form of impact may generate delamination damage, which will significantly reduce the residual strength of the component.

To overcome this limitation it is possible to adopt many 'damage tolerant design' techniques. Thicker and thus stiffer components will make them more resilient to out of plane loading but with a weight penalty. Use of tougher matrix constituents with a plastic phase will improve the overall performance but only up to a limit [1,2]. Use of interleaving materials at the critical interfaces where delaminations may initiate is another popular method [3,4]. Modern composite systems are increasingly employing such technologies, which have provided significant performance enhancements compared to earlier generations of composite materials. 
55 For largescale delamination damage, through thickness reinforcement (TTR) technologies have been shown to be quite effective [5]. In these methods, fibres or small rods are inserted in the composite materials reinforcing the thickness direction of the laminate. One of these techniques, also known as Z-pinning is a popular method used to reinforce pre-preg composite laminates. By inserting small stiff, fibrous composite rods in the thickness direction, this helps bridge the delamination interface tractions and thus provides excellent damage resistance capability [6].

Resistance of TTR composites to delamination has been subject to many studies, including quasi-static [6-8] and fatigue loading [9]. However, experimental investigations on the response of TTR composites when subjected to dynamic loading is limited and not well understood.

Investigations on the strain rate dependency of the constitutive mechanical properties of composite materials has produced many contradicting results as highlighted by Gerlach et. al. [10]. Investigations have shown tensile strength and stiffness can either increase, decrease or be independent of strain rate. Strain rate dependency of delamination fracture toughness has also exposed conflicting results as reviewed comprehensively by Jacob et. al. [11], highlighting experimental investigations that have demonstrated increases, decreases and independence of fracture toughness with strain rates. However from a closer look at the literature, some trends becomes apparent. For thermosetting un-toughened epoxy composites, delamination fracture toughness has either an increase $[12-14]$ or no significance $[15,16]$ with increased loading rate. Whereas thermoplastic composites have shown strong negative strain rate dependency, with delamination fracture toughness decreasing with increase in loading rate [15,17-19]. Ductile thermoplastics materials are well known to exhibit 
brittle fracture when subjected to increased strain rates [20], whereas fracture in brittle epoxies do not exhibit as strong strain rate dependence [21].

Dynamic fracture of materials is a specialist field of interest in material engineering [22] with a wide range of studies exploring fracture of materials from the fundamental atomic scale to large geological cases. Of particular interest is the concept of a limiting speed of crack propagation rate $\left(a^{*}=\partial a / \partial t\right)$ which has been shown to be equal to the materials' shear wave speed $\left(C_{s}\right)$ when loaded in mode I, whilst in mode II the delamination rate can increase beyond the shear wave speed reaching a critical velocity $\left(V_{C}\right)$ which is approximately equal to $\sqrt{2} C_{S}$ [23]. These extreme shear crack velocities have been achieved in edge notched composite plates where loading is directly transferred to the generation of the crack front, through a specific 1point bend configuration. Measuring crack velocities is challenging and often requires special detection gauges [24] or high resolution, high speed photography in excess of 50,000 frames per second (fps) to deduce the crack tip propagation reliably. For this reason only a few investigations exist in literature where delamination velocity in a standard fracture test has been measured. In mode I using a double cantilever beam (DCB), delamination speeds have been shown to reach up to $20-80 \mathrm{~m} / \mathrm{s}$ [15] for loading rate of $10 \mathrm{~m} / \mathrm{s}$. In mode II delamination speeds have shown to reach up to $130 \mathrm{~m} / \mathrm{s}$ using an end loaded split (ELS) specimen [25]. Tsai et. al. [24] and Guo et. al. [26] used a specific quasi-static test setup in which strain energy at the crack tip was built up with the use of interleaved toughening strips in a $3 \mathrm{ENF}$ and DCB specimen respectively. This build of strain energy in the sample thus allowed for control of the propagation rate of the delamination. Using this technique delamination speeds of up to $1100 \mathrm{~m} / \mathrm{s}$ in mode II and 330m/s in mode I were reported, respectively. 
103 It is quite evident that loading rate will only influence the fracture toughness of a

104 material when the stress waves travelling in the body directly alter the stress states in

105 the plastic zone ahead of a crack tip. For this reason factors such as loading/boundary

106 conditions as well as geometric shape of the component will greatly influence the

107 dynamic response of a component. Therefore direct comparison of the loading, strain

108 and crack propagation cannot be readily made and could be one major reasons behind

109 contradicting results in literature, particularly in regard to epoxy based composite

110 delaminations.

111 A feature unique to laminated composites that has shown to have a direct dependence

112 on strain rate is the apparent mode II fracture toughness of interlaminar toughening

113 techniques such as interleaving or TTR. Jiang et. al. [27] showed a direct linear

114 increase in fracture toughness of a thermosetting composite with a toughened epoxy

115 interleave phase. With a modest loading rate increase of $1-100 \mathrm{~mm} / \mathrm{min}$ up to $84 \%$

116 increase in apparent $\mathrm{G}_{\text {IIC }}$ was reported. Colin de Verdiere et. al. [25] reported a

117 modest increase of approximately $26 \%$ in the initiation apparent $\mathrm{G}_{\text {IIC }}$ of tufted

118 composite specimens loaded up to a rate $7 \mathrm{~m} / \mathrm{s}$. For Z-pinned composites the mode I

119 apparent fracture toughness appears to reduce with an increase in loading rate as

120 shown by Liu et. al. [28].

121 There are very few papers in the open literature concerned with the strain rate

122 dependency of Z-pinned composites (e.g. [29]). The objective of this paper was to

123 investigate the mode II aparent fracture toughness of a laminated composite

124 reinforced in the thickness direction using with Z-pins made from carbon fibre

125 reinforced plastic (CFRP) rods. These tests were carried out at displacement loading

126 rates from quasi-static up to $5 \mathrm{~m} / \mathrm{s}$. A comprehensive analysis of the composite 
response was made to conclusively show the effect of strain rate on the delamination resistance in un-reinforced and TTR epoxy based composites.

129

\section{Experimental test procedure}

\subsection{Materials and specimen preparation}

Specimens were manufactured using IM7/8552 prepreg (Hexcel, UK) stacked in a

Zero Dominated (ZD) sequence of $\left[(0,-45,0,+45)_{3 S}\right]_{S}$ to achieve a nominal

thickness of $6 \mathrm{~mm}$, with a $13 \mu \mathrm{m}$ PTFE film placed at the mid plane interface to form a starter crack, which falls between two $0^{\circ}$ plies, preventing any out of plane crack migration. The effective laminate properties were calculated using laminate theory and anisotropic material properties of a single UD ply (Table 1) with axis definitions as shown in Figure 2. The test procedure followed the standard 3 point bend end notched flexure (3ENF) [30] shown in Figure 1 with varying loading displacement rates $(\dot{\delta})$.

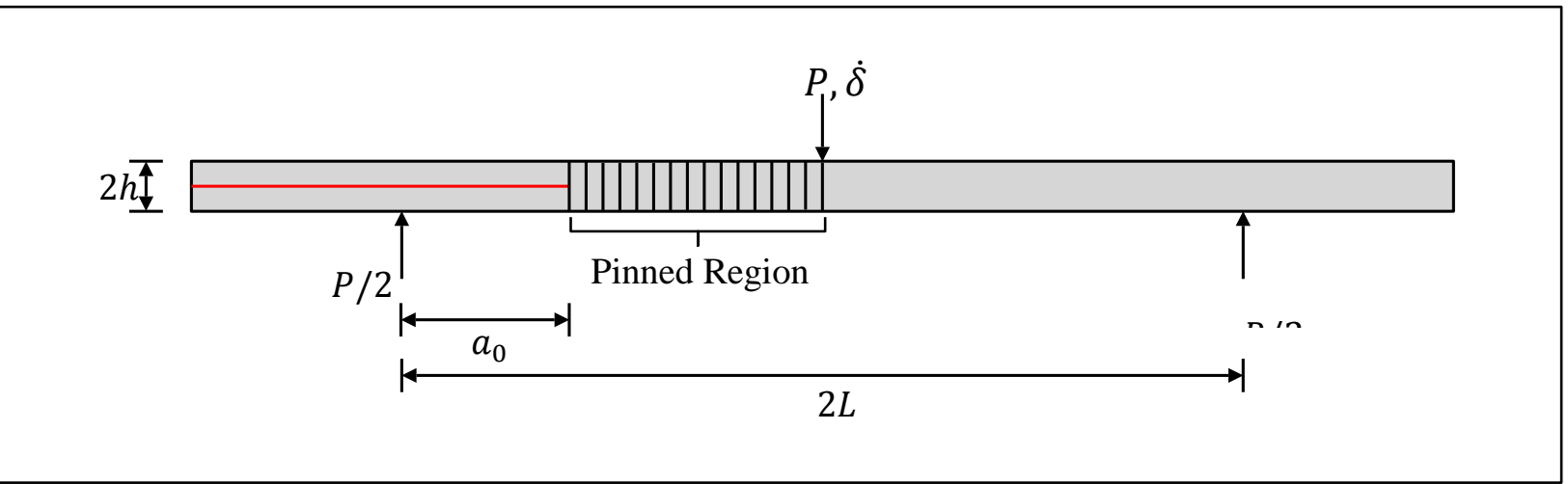

\section{Figure 1 3ENF test setup}

The Z-pinned specimens where pinned with T300 carbon/BMI pins arranged in a grid pattern with a spacing of $1.75 \mathrm{~mm}$, generating a nominal $2 \%$ areal density. Both the control and the Z-pinned samples were machined from a single plate, ensuring consistency in the material properties across both sample sets. 


\begin{tabular}{llllll}
\hline E1 & $90.83 \mathrm{GPa}$ & $\mathbf{G 1 2}$ & $23.37 \mathrm{GPa}$ & $\mathbf{v 1 2}$ & 0.71 \\
$\mathbf{E}_{2}$ & $26.44 \mathrm{GPa}$ & $\mathbf{G} 13$ & $4.86 \mathrm{GPa}$ & $\mathbf{v 1 3}$ & 0.14 \\
$\mathbf{E} 3$ & $13.18 \mathrm{GPa}$ & $\mathbf{G 2 3}$ & $4.23 \mathrm{GPa}$ & $\mathbf{v 2 3}$ & 0.37
\end{tabular}

147

148

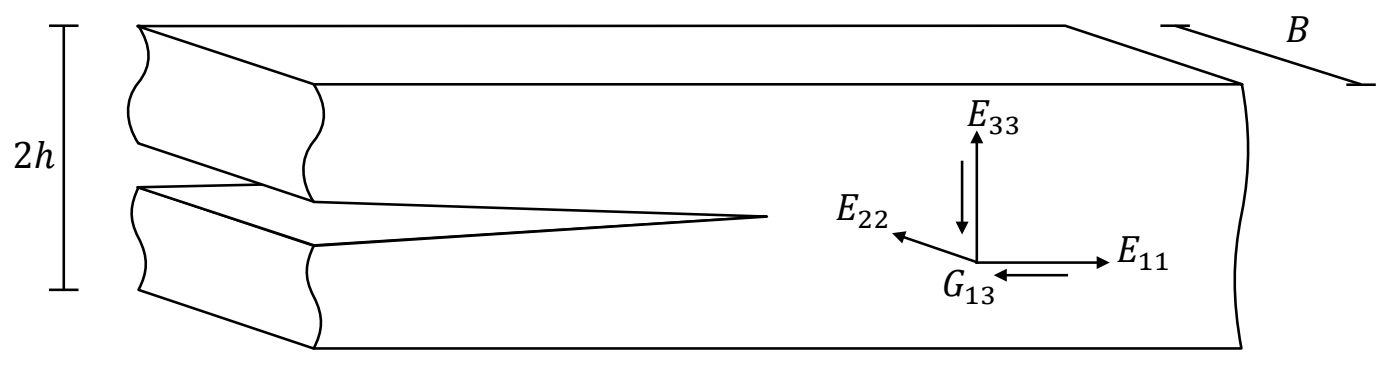

Figure 2 Composite laminate axis definitions

\subsection{Specimen Preparation}

Each specimen was machined to a nominal width of $20 \mathrm{~mm}$. The un-cracked part of each individual specimen was tested in a 3 point bend (3PB) following the ASTM-

790 [31] test standard to measure the flexural modulus $\left(E_{1 f}\right)$ of the material. The width $(B)$ and thickness $(2 h)$ of each specimen was measured at three different locations along its length to an accuracy of $\pm 0.05 \mathrm{~mm}$. For each specimen, a natural mode II pre-crack from the starter film was created using the procedure set out in ASTM-D7905 [30] to generate an initial crack length $\left(a_{0}\right)$ of $20 \mathrm{~mm}$ when positioned in the final test configuration. This resulted in 30mm of uncracked laminate and reinforced region ahead of the crack for the control and Z-pinned samples respectively. To ensure that the initial crack length was correctly determined, each sample was non-destructively tested using an ultrasonic C-scan technique and the average crack front measured as shown in Figure 3. 
163 Each edge of the specimens was painted with a speckle pattern to measure full field

164 strain and obtain accurate displacement measurements.

165

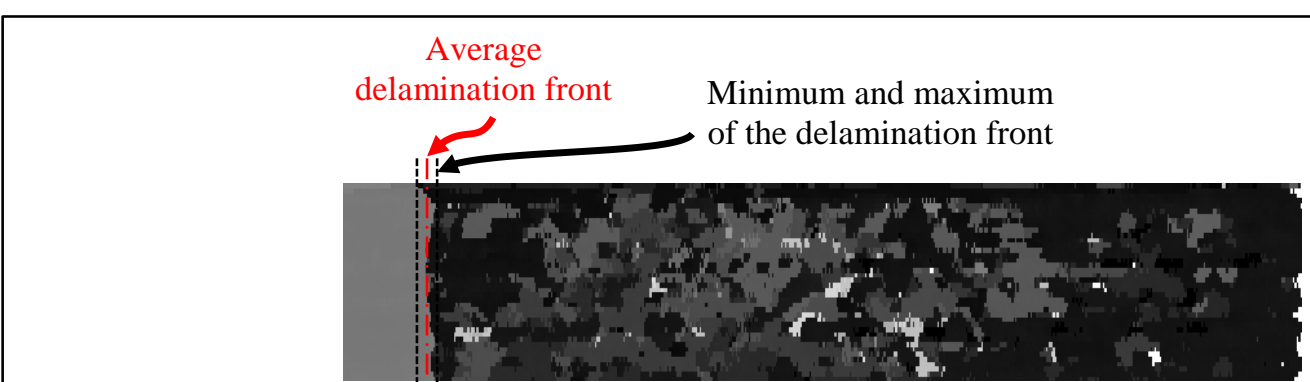

(a) Control

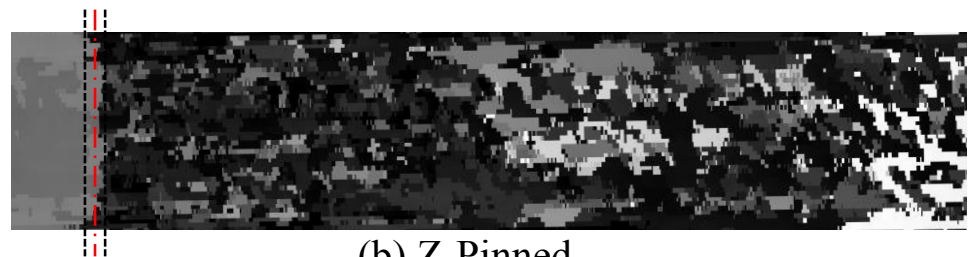

(b) Z-Pinned

Figure 3 Example of ultrasonic C-scan of (a) control and (b) pinned samples to determine the average natural pre-crack position

\subsection{Test procedures}

The ENF tests were performed with increasing displacement loading rates from quasistatic $\left(8.3 \times 10^{-6} \mathrm{~m} / \mathrm{s}\right)$, to intermediate $(1-4 \mathrm{~m} / \mathrm{s})$ and high $(5.5 \mathrm{~m} / \mathrm{s})$ on three different test apparatus. For all tests the support roller half span $(L)$ was set at $50 \mathrm{~mm}$ with an initial crack length $\left(a_{0}\right)$ of $20 \mathrm{~mm}$ and support roller and loading nose diameter of $10 \mathrm{~mm}$. The displacement and the crack propagation for all tests was monitored using a high definition imaging for quasi-static tests and high speed photography with a minimum of $100,000 \mathrm{fps}$ for the high loading rate tests. The camera was set up to ensure on average a 12pixel to mm resolution. This ensured sufficient resolution was available for full field strain measurements.

\subsection{Quasi-static}

The quasi-static 3ENF tests were carried out according to the ASTM-D7905 [30]

standard with a loading displacement rates of $0.5 \mathrm{~mm} / \mathrm{min}\left(8.3 \times 10^{-6} \mathrm{~m} / \mathrm{s}\right)$. The load was 
measured using a calibrated $5 \mathrm{kN}$ load cell on a hydraulic Instron test machine. For

182 these tests, the delamination is unstable for the length of the specimen being

183 measured. Therefore, the maximum load corresponds to the initiation of delamination

184 which is the critical load to use in the data reduction equations.

\section{$185 \quad 2.5 \quad$ Intermediate tests}

186 Intermediate loading displacement rate 3ENF tests were carried out on an

187 instrumented drop weight impact tower. For these tests a cylindrical loading nose was

188 attached to the end of a calibrated piezo-electric load-cell. The loading displacement

189 rate was varied by raising the entire impactor unit weighing $6.21 \mathrm{~kg}$ to a specific

190 height above the top surface of the laminate.

\subsection{High rate tests}

192 High loading displacement rate 3ENF tests were carried out using a Modified

193 Hopkinson Bar apparatus shown in Figure 4. The setup follows closely the impact

194 bending test procedure carried out by Hallett [32], Gerlach et. al. [33] and Wiegand et.

195 al. [34]. A striker bar of length $L_{s t r}$, is accelerated using compressed air to strike an

196 instrumented impactor bar of length $L_{i m p}$ with the same mechanical impedance and

197 diameter. This impact then generates a stress pulse of duration of $2 L_{s t r} / c_{0}$, where

$198 c_{0}=\sqrt{E / \rho}$ is the $1 \mathrm{D}$ longitudinal wave speed in the bar termed bar velocity. It is

199 desirable to position the first strain gauge at a distance of $d_{1}$ such that $L_{s t r}<\left(L_{i m p}-\right.$

$200 d_{1}$ ) to ensure that the incident pulse and the first reflected pulse from the striker bar

201 does not superimpose. This transfer of kinetic energy then accelerates the impactor

202 bar to a specific impact velocity generating the loading rate required to deform the

203 specimen. The material and geometrical properties for both the striker and the impact

204 bar and the strain gauge positions are given in Table 2. 


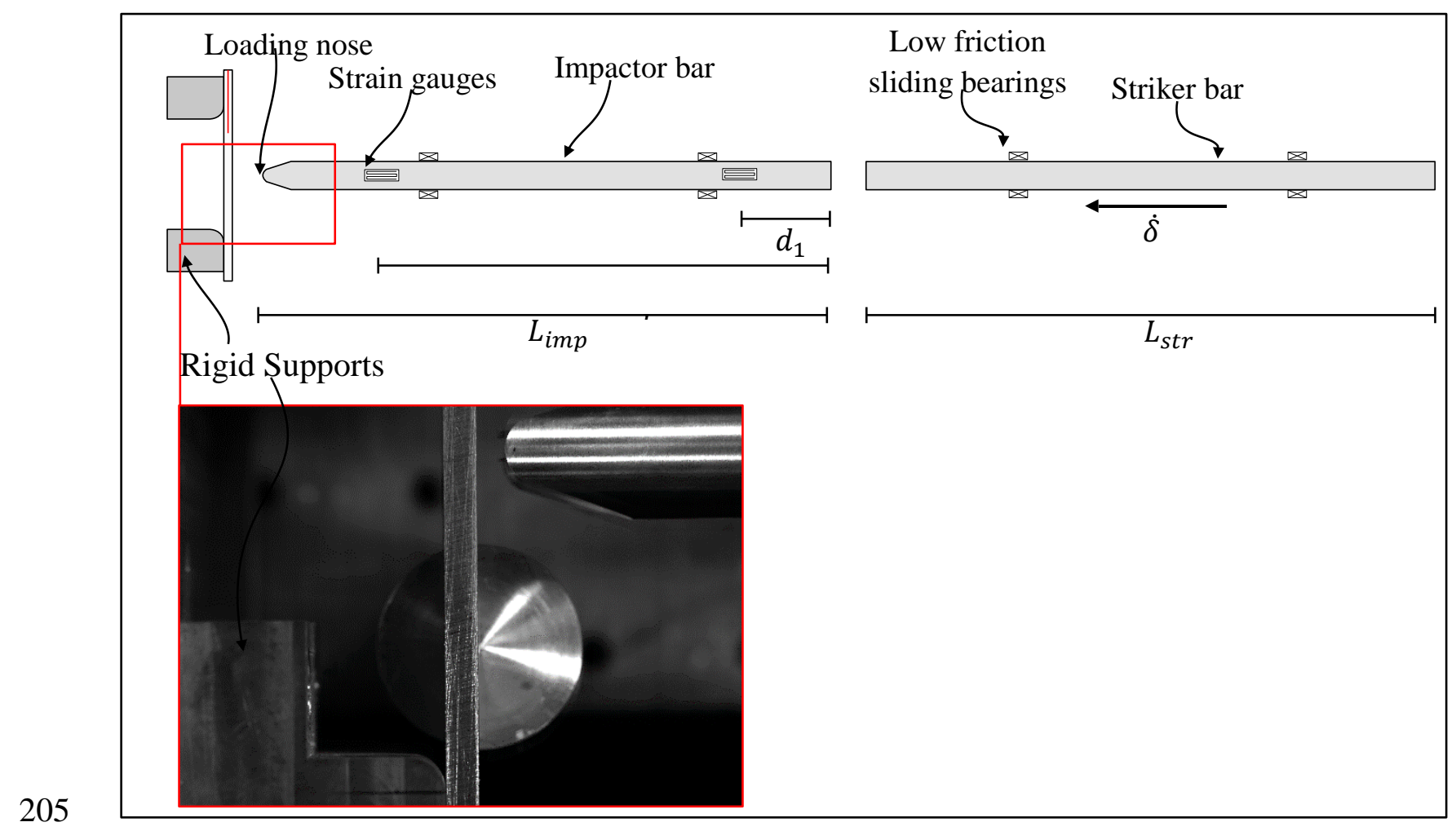

206 Figure 4 SHPB test setup

Table 2 SHPB Properties

\begin{tabular}{ll}
\hline Material & Titanium Alloy \\
& Ti-6Al-4V \\
& $($ Grade 5$)$ \\
& $113.8 \mathrm{GPa}$ \\
Modulus, $\boldsymbol{E}$ & $4430 \mathrm{~kg} / \mathrm{m}^{3}$ \\
\hline
\end{tabular}

Striker Bar

\begin{tabular}{ll}
\hline Length, $\boldsymbol{L}_{\text {str }}$ & $2.7 \mathrm{~m}$
\end{tabular}

Diameter 20mm

Mass $3.758 \mathrm{~kg}$

\section{Impactor Bar}

\begin{tabular}{ll}
\hline Length, $L_{i m p}$ & $3.0 \mathrm{~m}$
\end{tabular}


Diameter $20 \mathrm{~mm}$
Mass
$4.175 \mathrm{~kg}$

Strain gauge $1, d_{1} \quad 0.215 \mathrm{~m}$

Strain gauge $2, d_{2} \quad 1.806 \mathrm{~m}$

209 Using two strain gauge stations set up in a half-bridge configuration on the impact bar

210 the magnitude of the stresses at those specific cross section in the bar can be

211 calculated. The motion of longitudinal waves in a cylindrical bar can be described

212 using the one-dimensional wave equation:

$$
\frac{\partial^{2} u}{\partial x^{2}}=\frac{1}{c_{0}^{2}} \frac{\partial^{2} u}{\partial t^{2}}
$$

213 The general solution to this wave equation can be expressed in terms of two arbitrary

214 functions, $f$ and $g$ that define the wave-forms traveling in the positive (forwards) and

215 negative (backwards) directions respectively.

$$
u(x, t)=f\left(x-c_{0} t\right)+g\left(x+c_{0} t\right)
$$

216 Following standard constitutive relationships, this can be written in the form:

$$
\frac{d u(x, t)}{d x}=\varepsilon(x, t)=f^{\prime}\left(x-c_{0} t\right)+g^{\prime}\left(x+c_{0} t\right)=\varepsilon_{1}(x, t)+\varepsilon_{2}(x, t)
$$

217 Where, $f^{\prime}\left(x-c_{0} t\right)$ and $g^{\prime}\left(x+c_{0} t\right)$ are replaced by the incident and reflected

218 strain functions $\varepsilon_{1}(x, t)$ and $\varepsilon_{2}(x, t)$ respectively. The stress $\sigma$ and particle velocity

$219 v$ at any point in the bar can also be defined using equation (3) as:

$$
\begin{gathered}
\sigma(x, t)=E\left(\varepsilon_{1}(x, t)+\varepsilon_{2}(x, t)\right) \\
v(x, t)=-\frac{E}{\rho c_{0}}\left(\varepsilon_{1}(x, t)-\varepsilon_{2}(x, t)\right)
\end{gathered}
$$


220 Where $\rho$ is the density, $E$ is the modulus and $c_{0}$ is the 1D impactor bar velocity.

221 Figure 5 shows the Langrangian (time-distance) diagram for a 1D wave propagation

222 in a cylindrical bar of length $L_{i m p}$ with two strain gauges at a distance $d_{1}$ and $d_{2}$ from

223 the striker/impactor contact end $(x=0)$. It is possible to calculate the total stress in

224 any cross section of the bar including the tip of the impactor using the time shifted

225 values from the strain gauge instrumentations. In this investigation the location of

226 interest was at the impactor tip, $x=L_{i m p}$. The forward and backward travelling

227 elastic strain waves at this location was determined using the following routine:

$$
\varepsilon_{1}\left(L_{i m p}, t\right)=\left\{\begin{array}{cc}
\varepsilon\left[d_{1}, t-\left(t_{3}-t_{1}\right)\right] & t<t_{4} \\
\varepsilon\left[d_{1}, t-\left(t_{3}-t_{1}\right)\right]-\varepsilon_{2}\left[L_{i m p}, t-\left(t_{4}-t_{1}\right)\right] & t \geq t_{4}
\end{array}\right.
$$

$$
\varepsilon_{2}(L, t)
$$$$
=\left\{\begin{array}{cc}
\varepsilon\left[d_{2}, t+\left(t_{3}-t_{2}\right)\right]-\varepsilon\left[d_{1}, t+\left(t_{3}-t_{2}\right)-\left(t_{2}-t_{1}\right)\right] & t<t_{\iota} \\
\varepsilon\left[d_{2}, t+\left(t_{3}-t_{2}\right)\right]-\left\{\varepsilon\left[d_{1}, t+\left(t_{3}-t_{2}\right)-\left(t_{2}-t_{1}\right)\right]-\varepsilon_{2}\left[L_{i m p}, t-2\left(t_{2}-t_{1}\right)\right]\right\} & t \geq t_{\iota}
\end{array}\right.
$$

228 Using equations (6), (7) and (4) the load at the end of an impactor bar with a cross

229 section area, $A$ is:

$$
F\left(L_{\text {imp }}, t\right)=A \sigma\left(L_{\text {imp }}, t\right)
$$




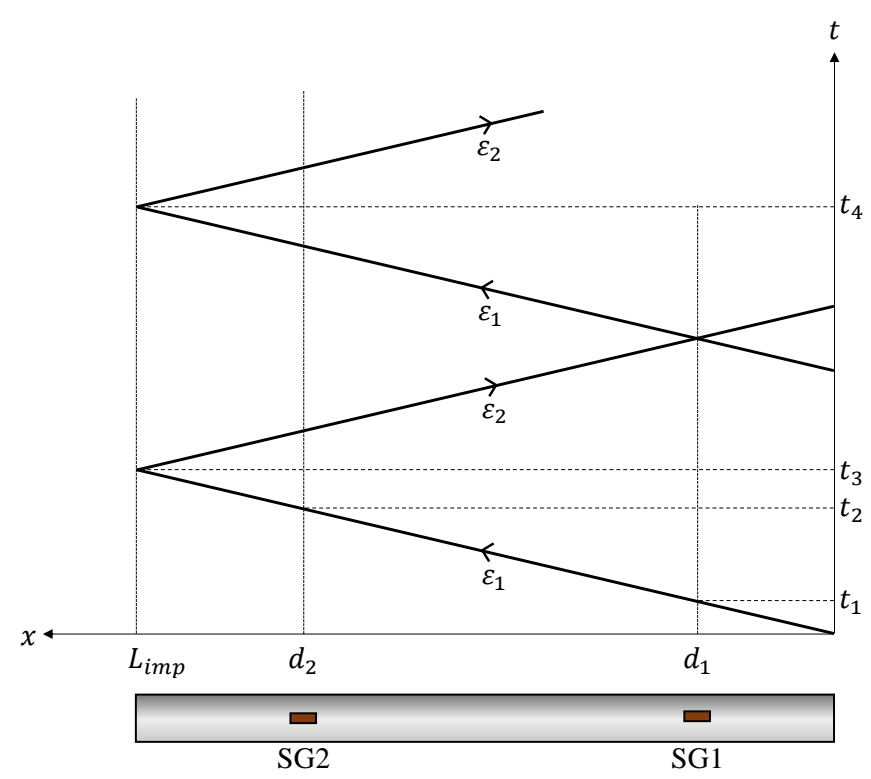

231 Figure 5 Langrangian diagram for longitudinal waves in cylindrical bar

232 The load signal calculated was further filtered to remove high frequency noise. A

$2331000^{\text {th }}$ order $1 \mathrm{D}$ median filter was found to effectively attenuate the high peak signals

234 which was not possible with a 500 point moving average smoothing technique, Figure

235 6. This plot also illustrates the load drops associated with delamination initiation and

236 subsequent fracture, as confirmed by the high speed footage.

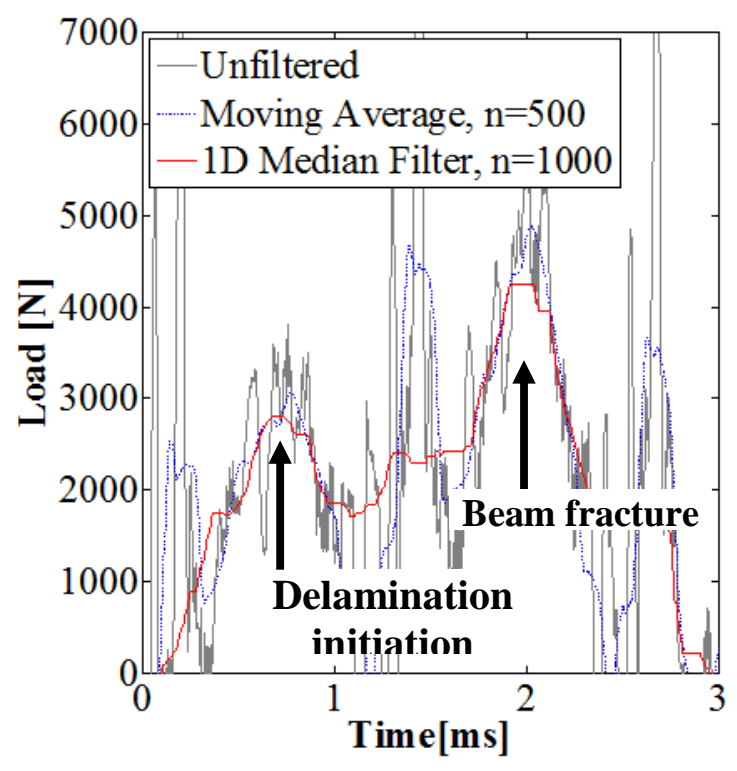

239 Figure 6 Example of filtration of the calculated load from the SHPB tests 
240 The wedge shaped tip of the impactor was designed in order to minimise the effect of

241 stress wave reflections along the impactor rod tip. Gerlach et. al. [33] and Wiegand et.

242 al. [34] have shown using FE analysis that the force obtained from stress wave

243 analysis compares well to the numerical simulations confirming that any inaccuracy

244 introduced by the geometry of the wedged tip is negligible.

\section{$245 \quad 2.7$ Data reduction technique}

246 Load response of a high rate test procedures suffer from high frequency oscillations

247 arising from dynamic effects as shown in previous section. The load output from the 248 drop-weight impact tower used in these experiments is filtered internally by the test 249 equipment which removes high frequency vibrations however inertial oscillations are 250 still visible in the response. These dynamic effects also increase with increasing 251 loading rates, thereby determining the critical load at the moment of initiation is not 252 possible [15]. For this reason, use of measured critical load in the data reduction 253 calculations will yield incorrect values of the materials fracture toughness.

254 It has been shown that CFRP laminates exhibit no observable strain rate dependency 255 in their axial modulus $E_{11}[15,35]$. It is thus possible to calculate $G_{\text {IIC }}$ using the 256 displacement at the moment of delamination initiation. This displacement can be 257 reliably measured using the high speed photography images from all loading rate test 258 procedures. The compliance of the 3ENF specimen [36] is given by:

$$
C=\frac{2 L^{3}+3 a^{3}}{8 E_{1 f} B h^{3}}+\frac{3 L}{10 G_{13} B h}
$$

259 The term on the right includes the influence of through thickness shear which is

260 dependent on the $h / L$ of the test setup. The inter-laminar fracture toughness is

261 calculated by measuring the strain energy release rate of the material, defined as: 


$$
G=\frac{1}{B} \frac{\partial(W-U)}{\partial a}
$$

262 where $W$ is the work applied by external forces and $U$ is the elastic strain energy.

263 Using equation (10) the mode II fracture toughness has been reduced [37] to be:

$$
\begin{gathered}
G_{I I C}=\frac{9\left(\frac{\delta}{C}\right)^{2}(a+0.42 \chi h)^{2}}{16 B^{2} E_{1 f} h^{3}} \\
\chi=\left[\frac{E_{11}}{11 G_{13}}\left(3-2\left(\frac{\Gamma}{1+\Gamma}\right)^{2}\right]^{1 / 2}\right. \\
\Gamma=\frac{1.18 \sqrt{E_{11} E_{33}}}{G_{13}}
\end{gathered}
$$

264 Where the term $0.42 \chi h$ is the correction added to the length of the crack to account

265 for the root rotation of the beam arms [37] and $E_{1 f}$ is the flexural modulus of the

266 material which was measured for each specimen independently in the current

267 experiments. The above equations do include two rate dependent properties, $G_{13}$ and

$268 E_{33}$ which have been shown to increase by $12 \%$ and $25 \%$ for strain rates up to $300 \mathrm{~s}^{-1}$

269 [38]. Assuming a maximum increase of $25 \%$ for these two properties will result in a

270 decrease of $0.11 \%$ in the calculated value of $G_{I I C}$. Therefore, any rate dependency of

$271 G_{13}$ and $E_{33}$ can be ignored.

272 In the high rate tests it has been argued that the kinetic energy of the body may

273 influence the strain energy release rate at the crack tip [17]. The total kinetic energy of

274 the system is defined as:

$$
T=\frac{1}{2} \rho_{c} B(2 h) \int_{-L}^{L}\left(\frac{d \delta}{d t}\right)^{2} d x
$$


275 Where $\rho_{c}$ is the density of the specimen being tested. Therefore the kinetic energy

276 contribution to the strain energy release rate, $G$ (equation (10)) for a specimen with

$277 \quad a / L=0.5$ was defined to be [17]:

$$
\frac{1}{B} \frac{\partial T}{\partial a}=-0.078 \rho h \dot{\delta}
$$

278 For the experimental loading rates (maximum $\dot{\delta} \approx 5.5 \mathrm{~m} / \mathrm{s}$ ) investigated, the kinetic

279 energy term can be seen to increase the fracture toughness by less than $1 \%$ of $G_{I I C}$.

280 Therefore it can be reasonably assumed that, for the tests carried out in this

281 investigation, the kinetic energy contribution is negligible and the quasi-static $G_{I I C}$

282 data reduction procedure to be valid.

283

\subsection{Tensile and Shear strain rate measurement}

The displacement, shear and tensile strains were measured using images extracted from video frames in quasi static tests and from high speed photography in the high rate tests. These image sequences were then post processed using a non-contact video extensometer software (Imetrum Ltd) to track specific points on the sample as shown in Figure 7. To verify these measurements, full field strain measurements were carried out using 2D digital image correlation (GOM UK Ltd) for a specimen in each test regime using the same image sequences. A least squares polynomial fit of the first degree (linear fit) was applied to the initial elastic region section of the strain curves to determine the strain rates for all samples respectively. 


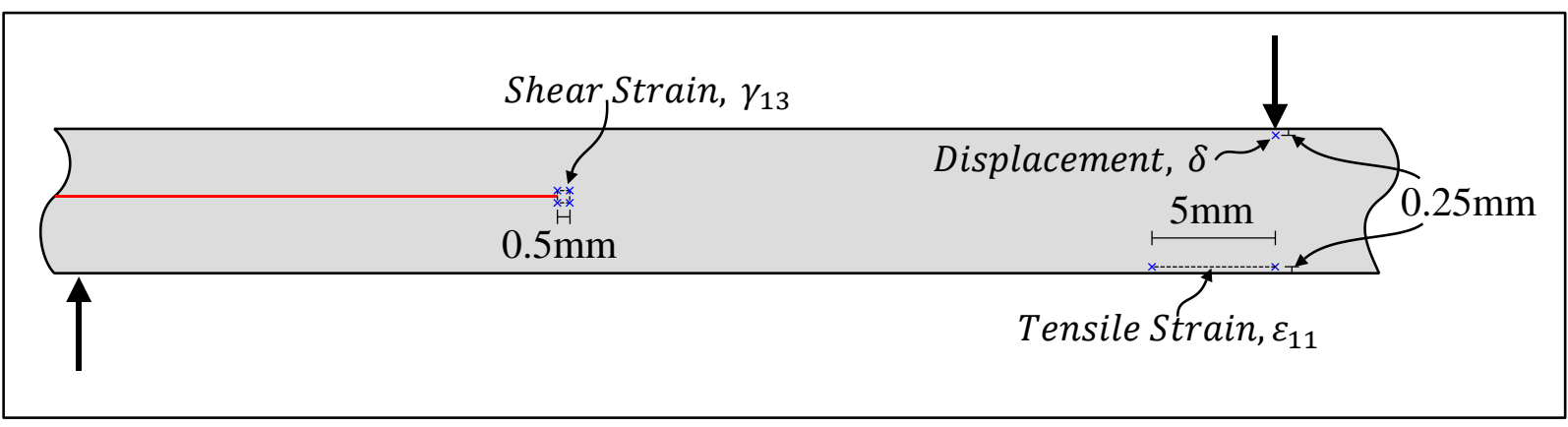

294 Figure 7 Displacement, tensile and shear strains measured using non-contact video extensometer 


\section{Results}

\subsection{Quasi-Static - Data reduction method comparison}

298 The load-displacement plot of the control and pinned samples is shown in Figure 8.

299 The quasi-static flexural tests of all the samples produced an average flexural

300 modulus, $E_{1 f}$ of $83.5 \pm 1.1 \mathrm{GPa}$. Figure 8 shows the theoretical compliance, calculated

301 using this flexural modulus with $a=20 \mathrm{~mm}, B=20 \mathrm{~mm}$. The mode II fracture

302 toughness of the initial non pre-crack (from $13 \mu \mathrm{m}$ PTFE release film) was measured

303 to be $1050 \pm 156 \mathrm{~J} / \mathrm{m}^{2}$. Following the standard ASTM 3ENF test procedure the fracture

304 toughness of the natural pre-crack $\mathrm{G}_{\text {IIC }}$ of the IM7/8552 was measured to be

$305663 \pm 100 \mathrm{~J} / \mathrm{m}^{2}$. Calculating the $\mathrm{G}_{\text {IIC }}$ using the compliance procedure described in

306 section 2.7 and equation (11) the fracture toughness was measured to be

$307673 \pm 112 \mathrm{~J} / \mathrm{m}^{2}$. With only $1.5 \%$ difference between the two procedures, the compliance

308 procedure can be accepted to produce correct values of the fracture toughness of the

309 material and gives confidence to use for the high rate procedure.

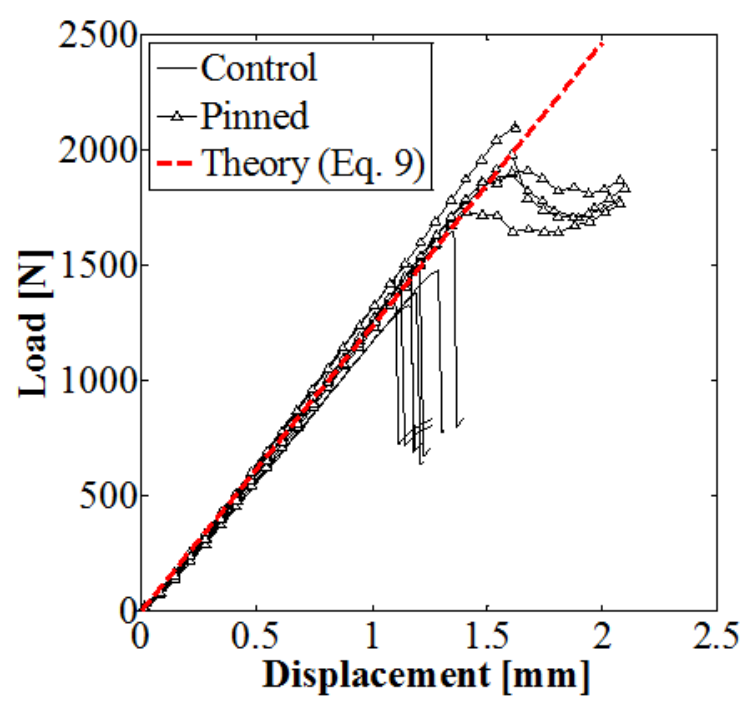

311 Figure 8 Load-displacement for control specimens along with average compliance using equation (9)

312 The average R curve for the control and pinned samples are shown in Figure 9. For

313 control samples, the 3ENF only produces a single critical strain energy release rate 
314 value at the moment of initiation due to the unstable nature of the crack, which is the

315 fracture toughness, $\mathrm{G}_{\text {IIC }}$ of the material. The pinned samples however produce an

316 increasing $\mathrm{R}$ curve with crack length due to the development of the extrinsic bridging

317 zone behind the crack tip. The average critical strain energy release rate at the

318 moment of initiation is $922 \pm 109 \mathrm{~J} / \mathrm{m}^{2}$, a minor increase relative to the control samples.

319 The critical strain energy release rate reaches a maximum of $2613 \pm 499 \mathrm{~J} / \mathrm{m}^{2}$ at a crack

320 length of $50 \mathrm{~mm}$. In this test configuration the maximum bridging zone length possible

321 is $30 \mathrm{~mm}$, however the fully developed Z-pin bridging zone length is expected to be

322 much longer than the $30 \mathrm{~mm}$ length, approximately between 40-60mm [39]. The

323 apparent fracture toughness increase of these tests agrees well with that previously

324 reported in literature $[6,39,40]$.

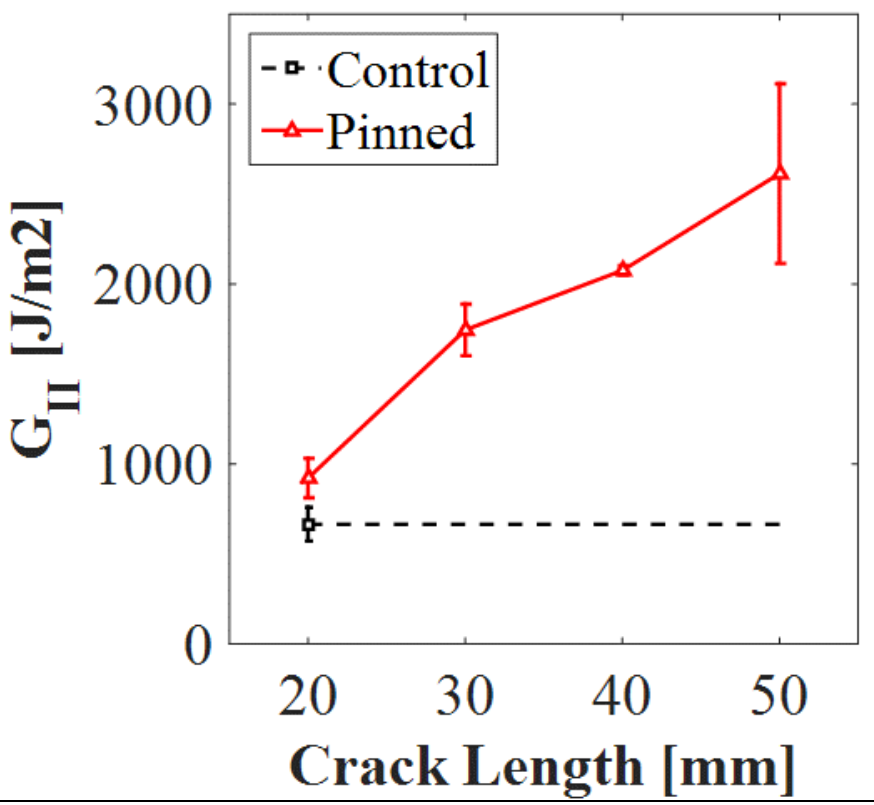

327 Figure 9 Average $R$ curve for control and pinned specimens

\subsection{Delamination velocity}

329 The delamination propagation rate $(\dot{a})$ was measured for each specimen directly from

330 the high speed imaging. An example of the control and pinned response to 
331 delamination initiation is shown in Figure 10. For consistency, $\dot{a}$ was calculated by 332 measuring the time taken for delamination to reach the middle loading nose $\sim 30 \mathrm{~mm}$.

333 For control samples the delamination was unstable and typically propagated past the

334 middle loading nose. For the pinned samples the delmination rate varied within this

335 distance, with an almost stick slip behavior.

336 The relationship between $\dot{a}$ and $\dot{\delta}$ is shown in Figure 11. For the control samples there

337 is a clear almost linear increase in the delamination propagation rate from $444 \mathrm{~m} / \mathrm{s}$ for 338 quasi-static loading rate up to $858 \mathrm{~m} / \mathrm{s}$ for $5.5 \mathrm{~m} / \mathrm{s}$ loading rate. For the pinned samples,

339 the delamination propagation rate was stable $\sim 4 \mathrm{~mm} / \mathrm{s}$ when loaded quasi-statically.

340 The propagation rate increase almost linearly from $\sim 10 \mathrm{~m} / \mathrm{s}$ for $1 \mathrm{~m} / \mathrm{s}$ loading rate up to $341 \sim 530 \mathrm{~m} / \mathrm{s}$ for $5.5 \mathrm{~m} / \mathrm{s}$ loading rate. 

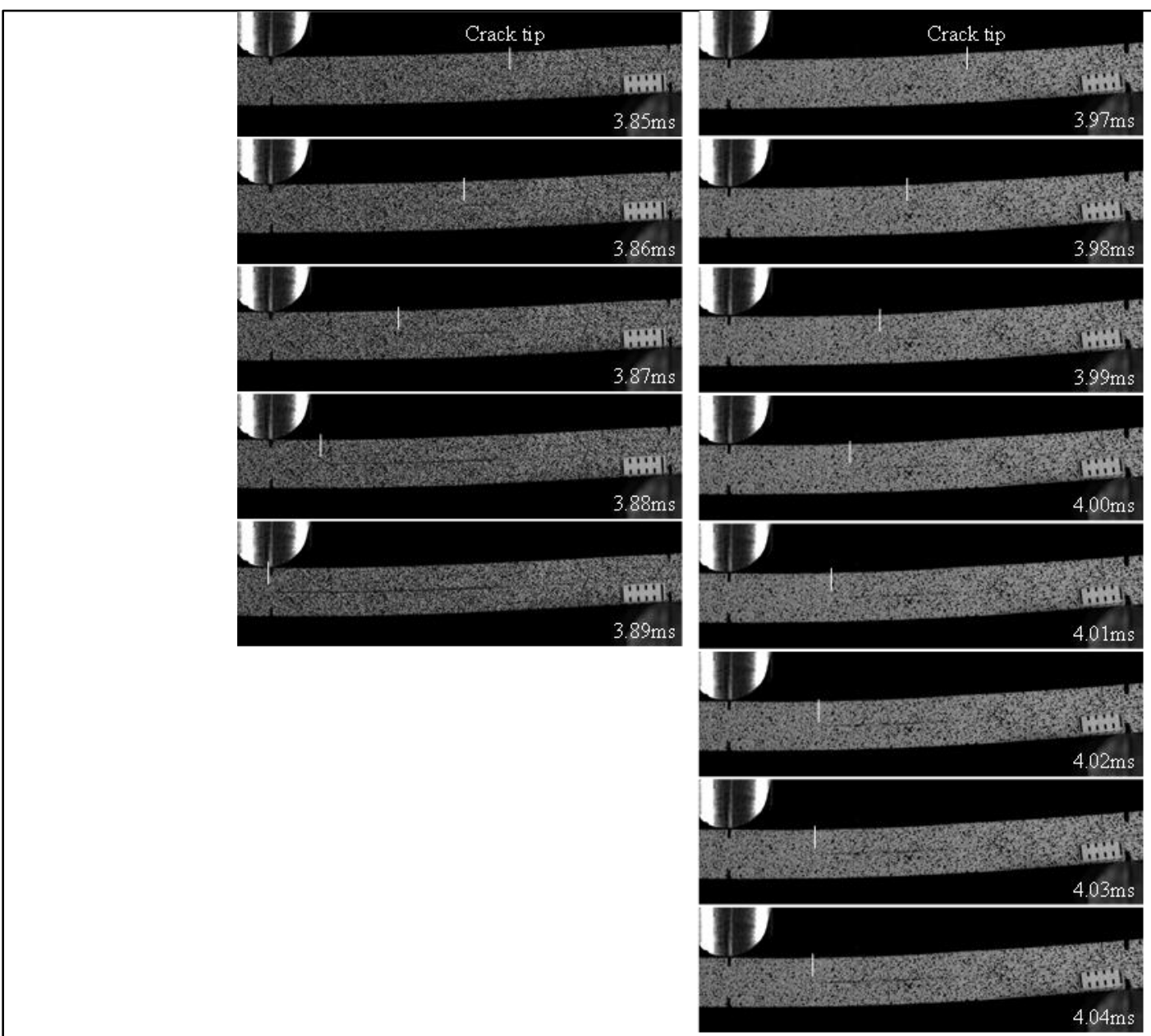

(a) Control

(b) Pinned

Figure 10 Example of the measurement of average delamination propagation rate $(\dot{a})$ of control and pinned 345 samples tested with loading rate $(\dot{\delta})$ of $3 \mathrm{~m} / \mathrm{s}$ 


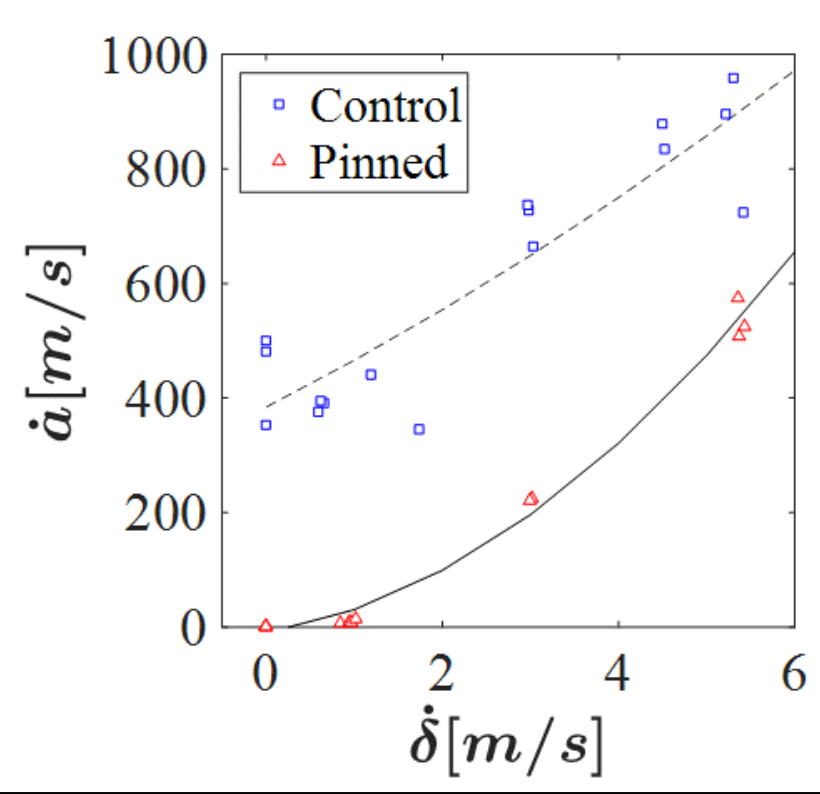

Figure 11 Delamination propagation rate $(\dot{a})$ against loading displacement rate $(\dot{\delta})$

\subsection{Tensile and Shear strain rate response}

350 The relationship of the shear strain rate $(\dot{\gamma})$ measured at the tip of the initial crack and

351 the tensile strain rate $(\dot{\varepsilon})$ measured at the mid span length on the lower surface of the

352 specimen against displacement loading rate $(\dot{\delta})$ is shown in Figure 12. The shear

353 strain rate reaches an average of $22 \mathrm{rad} / \mathrm{s}$ for samples tested at $\dot{\delta}$ of $5.3 \mathrm{~m} / \mathrm{s}$. The

354 increase in $\dot{\gamma}$ with $\dot{\delta}$ is approximately linear. The maximum tensile strain rate

355 achieved in this investigation was on average $13 \mathrm{~s}^{-1}$ for samples tested at $\dot{\delta}$ of $5.3 \mathrm{~m} / \mathrm{s}$. 


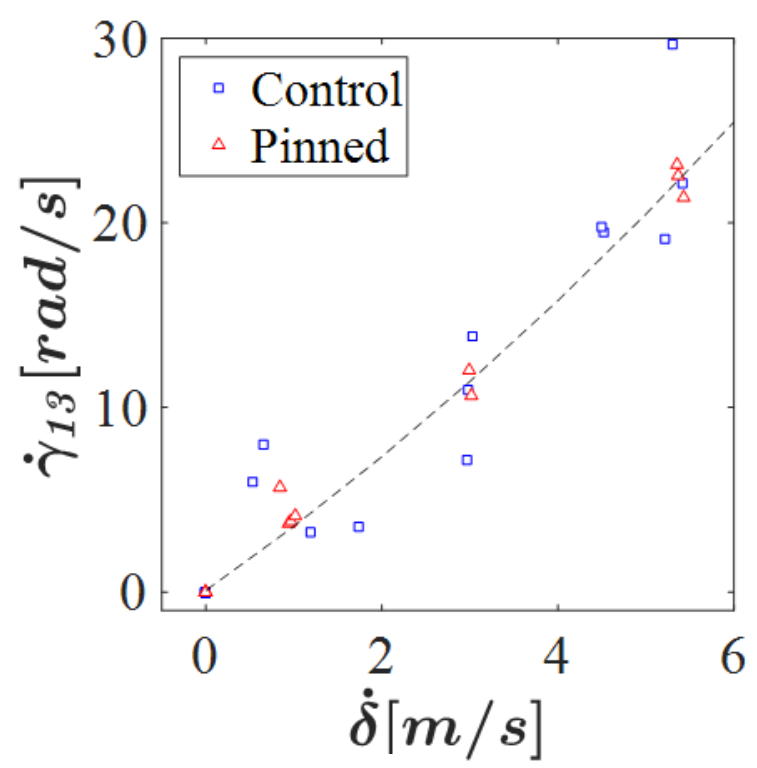

(a)

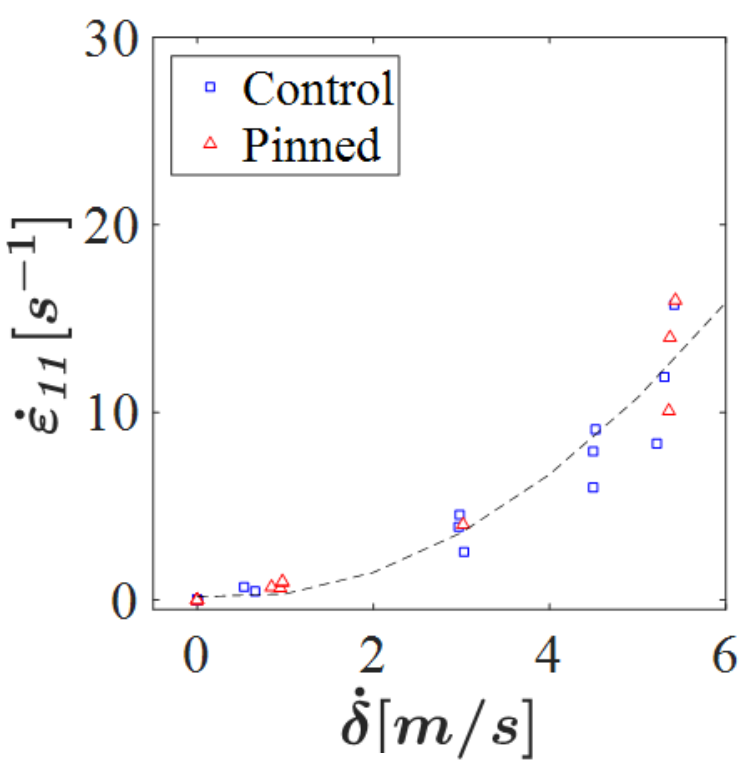

(b)

Figure 12 Loading displacement rate $(\dot{\delta})$ against (a) shear strain rate $(\dot{\gamma})$ and (b) tensile strain rate $(\dot{\varepsilon})$

\subsection{Load-displacement response}

The load-displacement plots for all the tests are given in Figure 13. With increase in displacement loading rate $\dot{\delta}$ the noise in the load output measured can be seen to increase and produce an unclear critical load prior to delamination. On these plots the loading displacement at which delamination initiated is highlighted. It can be seen that the critical load cannot be taken directly from the load displacement responses necessitating the use of the compliance procedure to calculate the GIIC of the specimens.

For the control samples, the load response appears to be constant with increasing $\dot{\delta}$.

For the pinned specimens, there is a significant increase in the initiation load with increase with $\dot{\delta}$. The pinned specimens maintain significant residual interlaminar strength after delamination initiation as compared to the control samples where there is a distinctly sharper load drop. 

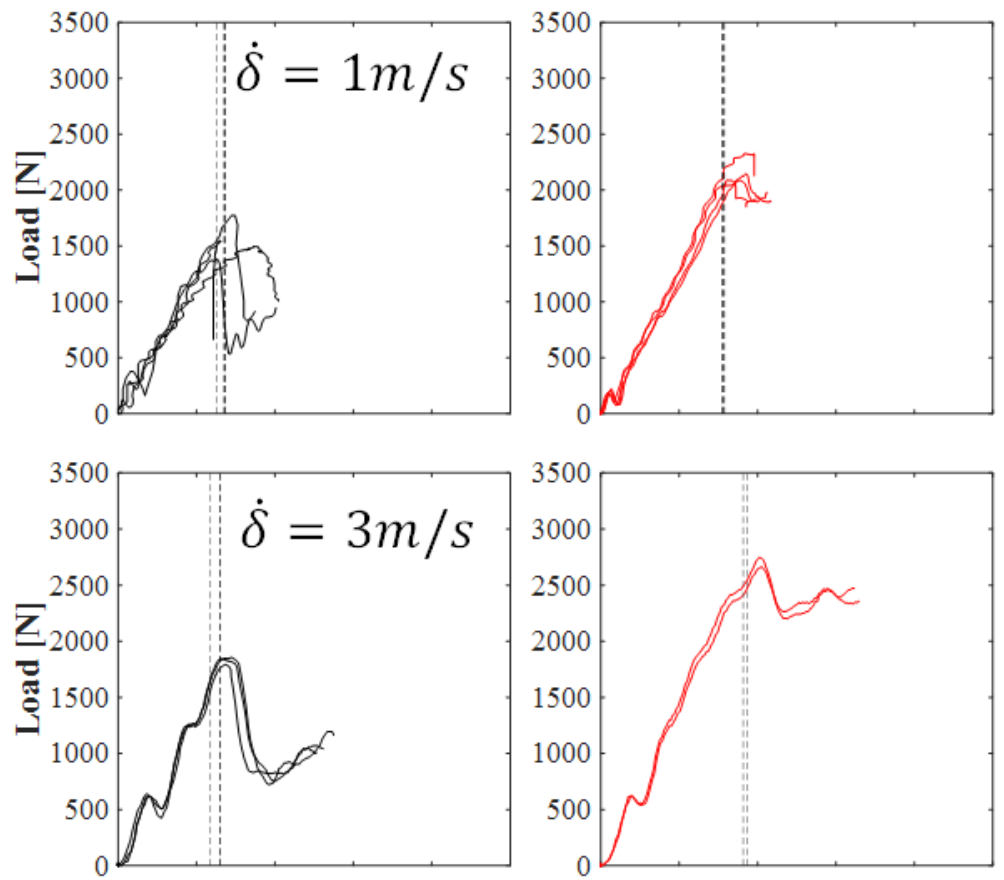

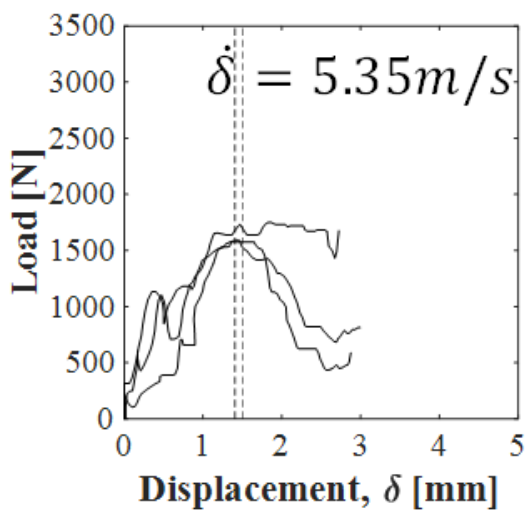

(a) Control

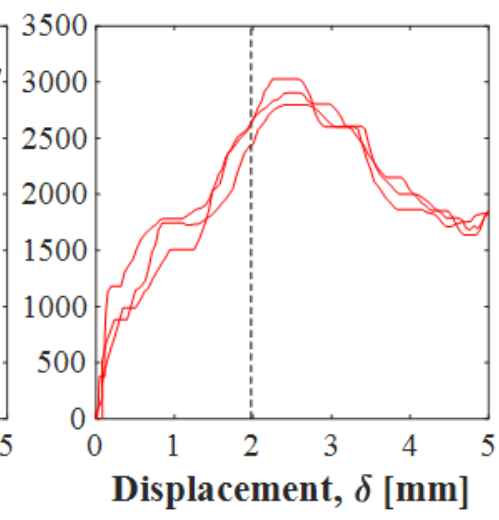

(b) Pinned

Figure 13 Load-displacement $(\delta)$ plots of for increasing loading displacement rate $(\dot{\delta})$, dashed lines indicate the displacement at which delamination initiated

\subsection{Rate dependence of interlaminar fracture toughness $\mathrm{G}_{\text {IIC }}$}

The calculated $\mathrm{G}_{\text {IIC }}$ at the moment of delamination initiation against loading

displacement rate $(\dot{\delta})$, shear strain rate $(\dot{\gamma})$ and delamination velocity $(\dot{a})$ is presented in Figure 14. The control samples produce a minor increase in the $\mathrm{G}_{\text {IIC }}$ with increase

378 in loading rate from $663 \pm 100 \mathrm{~J} / \mathrm{m}^{2}$ for quasi-static tests to $970 \pm 90 \mathrm{~J} / \mathrm{m}^{2}$ for $\dot{\delta}$ of $5.3 \mathrm{~m} / \mathrm{s}$.

379 The pinned samples showed a very strong increase in $\mathrm{G}_{\text {IIC }}$ with increase in loading rate. With initiation G IIC $_{\text {of }} 922 \pm 109 \mathrm{~J} / \mathrm{m}^{2}$ for quasi-static tests to $2002 \pm 64 \mathrm{~J} / \mathrm{m}^{2}$ for $\dot{\delta}$ of 
$3815.3 \mathrm{~m} / \mathrm{s}$. Since the relationship between shear strain rate and displacement rate is

382 almost linear (Figure 12a) the response of $G_{I I C}$ in Figure 14a and Figure 14b produce

383 similar profile. The relationship between GIIC and delamination velocity is

384 approximately linear with very minor increase for the control samples. However, for

385 the pinned samples, there is significant increase in $G_{I I C}$ before what appears to be a

386 plateau forming above $500 \mathrm{~m} / \mathrm{s}$. Whether the $G_{I I C}$ will increase with increase in

387 delamination velocity will need to be investigated further.

388

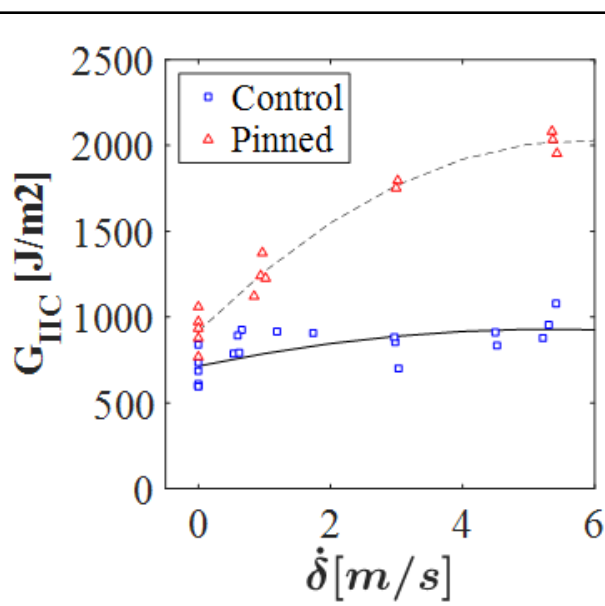

(a)

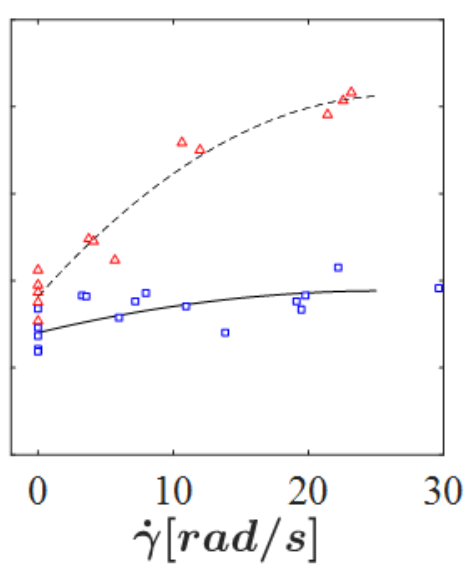

(b)

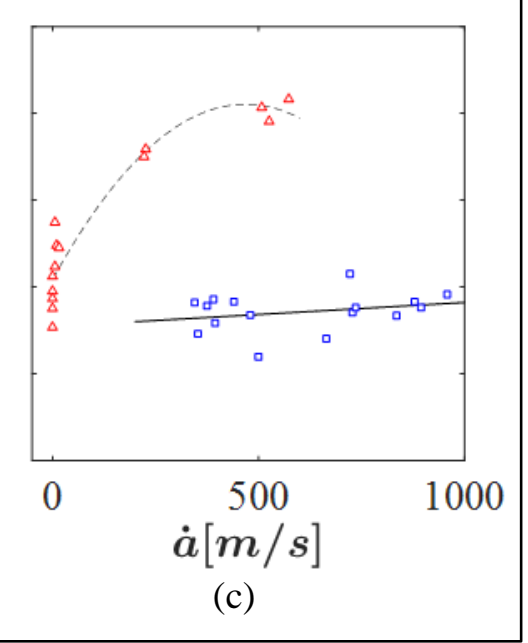

(c)

Figure 14 GIIC plots of for increasing (a) loading displacement rate $(\dot{\delta})$, (b) shear strain rate $(\dot{\gamma})$ and (c) delamination velocity $(\dot{a})$

\section{Fractography}

A representative control and pinned specimen from each loading rate batch was manually opened and the fracture surface was observed using scanning electron microscope (SEM) imaging. It was seen that the failure profile of the pinned specimens produce two distinct morphology and this morphology was seen to transition for samples tested with loading rates above $3 \mathrm{~m} / \mathrm{s}$. Figure 15 and Figure 16 show the fracture surfaces of specimens loaded quasi-statically and at a loading rate $\dot{\delta}$ of $5.3 \mathrm{~m} / \mathrm{s}$ respectively. The fracture surfaces of the control samples tested did not 
400 show any significant change in surface profile, with typical shear hackles present. The 401 pinned samples tested quasi-statically showed the standard profile observed in many 402 other mode II fracture tested quasi-statically $[6,39,41]$, in that the pins begin to pull403 out, bend and deform before rupture. Figure $15 \mathrm{~b}$ and $\mathrm{c}$ show the small bulge of the 404 pulled-out pin that has been ruptured in a shear dominated form. Pinned specimens 405 exhibiting this failure mode will experience a long mode II bridging zone length and 406 the fracture process observed on a macro scale may be similar to a highly ductile 407 delamination crack.

408 Figure 16b and c however exhibit a flush, shear failure of the pins. This behavior is 409 reminiscence of a highly brittle fracture and has occurred in specimens tested above $4103 \mathrm{~m} / \mathrm{s}$ loading rate. This behavior corresponds to a mode II delamination with a short 411 bridging zone length, since the pins do not have the time to deform, pull-out and 412 rupture. This is highlighted in the increased initiation $\mathrm{G}_{\text {IIC. }}$. Furthermore, the increase 413 in GIIC does appear to reach an upper level plateau. This limit can be equated to an 414 experimentally and analytically predicted value of approximately $3400 \mathrm{~J} / \mathrm{m}^{2}$ for a $4150.28 \mathrm{~mm}$ diameter, T700/BMI pin inserted in an array of $2 \%$ nominal areal density 416 [42-44]. 

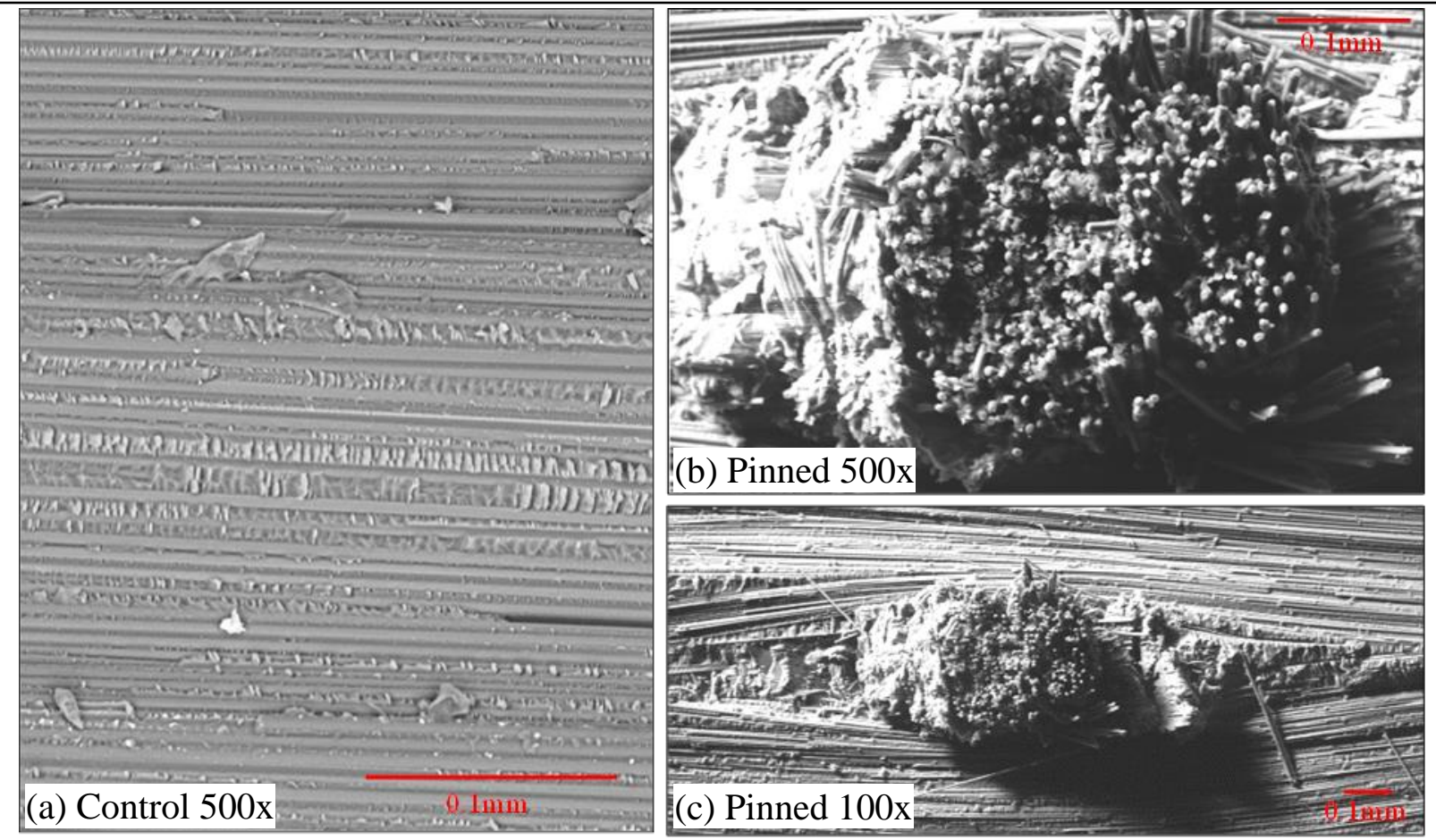

418 Figure 15 SEM imaging of the fracture surface of (a) control and (b,c) pinned specimens loaded quasi-

419 statically 

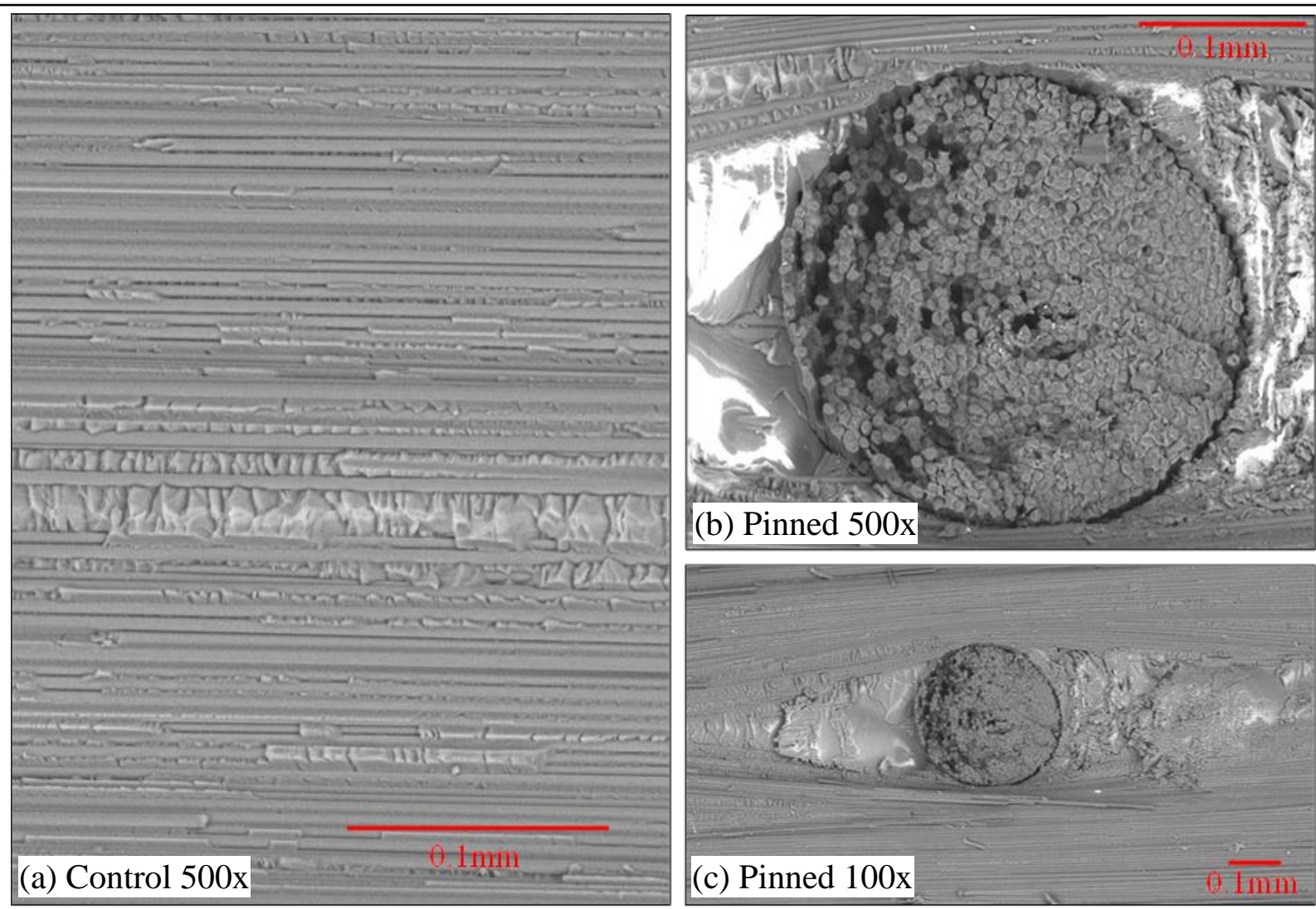

422 Figure 16 SEM imaging of the fracture surface of (a) control and (b,c) pinned specimens test with loading

423 displacement rate of $5.3 \mathrm{~m} / \mathrm{s}$

\section{Discussions and Conclusions}

425 A comprehensive experimental characterisation of a mode II delamination in a Z-pin

426 reinforced and unreinforced laminated composite has been carried out with increasing

427 strain rates. Tests were performed on standard hydraulic test machines for quasi-static

428 tests, instrumented drop-weight impact tower for intermediate loading rates and a

429 bespoke modified Hopkinson Bar apparatus for high loading rates. The procedure

430 followed to measure the $\mathrm{G}_{\text {IIC }}$ of the material used a compliance based approach rather

431 that the standard load based data reduction techniques. Assuming that the flexural

432 modulus of the beams are rate independent the $\mathrm{G}_{\text {IIC }}$ of each specimen was calculated

433 using the loading nose displacement at moment of delamination initiation. This

434 procedure removed the need to deduce the critical load at initiation as the load

435 response was clearly shown to be unreliable due to the excessive dynamic noise in the 
output results. Furthermore each specimen that was tested was pre-prepared to ensure

437 a natural sharp mode II crack was created and quasi-static test showcased a good

438 agreement in $\mathrm{G}_{\text {IIC }}$ between the ASTM standard and the compliance method described 439 here.

440 The maximum delamination velocity achieved in the unreinforced tests was on 441 average $858 \mathrm{~m} / \mathrm{s}$ for $5.5 \mathrm{~m} / \mathrm{s}$ displacement loading rate. Falling far below the shear 442 wave speed, calculated for the current IM7/8552 composite system to be $1933 \mathrm{~m} / \mathrm{s}$. 443 This highlights that higher theoretical delamination propagation rates exist and may 444 be achieved when the composite system is loaded at loading rates above $5 \mathrm{~m} / \mathrm{s}$. The 445 results show that the average delamination velocity for a composite laminate will 446 increase almost linearly with increasing displacement loading rate. The range of 447 loading rates attempted in this investigation was from quasi-static to $\sim 5.3 \mathrm{~m} / \mathrm{s}$. The 448 mode II fracture toughness of the composite was seen to have a minor increase from $449663 \pm 100 \mathrm{~J} / \mathrm{m}^{2}$ to $970 \pm 90 \mathrm{~J} / \mathrm{m}^{2}$ confirming behaviours observed in literature for tests on 450 thermosetting brittle epoxy composites, where either minor or no significant increase 451 in $\mathrm{G}_{\text {IIC }}$ were reported.

452 Mode II delamination in through-thickness reinforced laminates were also 453 characterised. These specimens exhibited a strong apparent fracture toughness 454 increase with displacement loading rate. It was shown that the initiation GIIC increases 455 from $922 \mathrm{~J} / \mathrm{m}^{2}$ to $2002 \mathrm{~J} / \mathrm{m}^{2}$ over the velocity range tested here. Through fracture 456 surface observations a transition in the failure profile of the Z-pins was revealed. Pins 457 tested at loading rates below $3 \mathrm{~m} / \mathrm{s}$ corresponding to delamination velocity of $458<<200 \mathrm{~m} / \mathrm{s}$ exhibit a fracture profile similar to those tested quasi-statically, with the 459 pins pulling-out, bending before failing in shear dominated rupture. At higher than $4603 \mathrm{~m} / \mathrm{s}$ loading rate the delamination velocity in the pinned samples was in excess of 
$461200 \mathrm{~m} / \mathrm{s}$, this resulted in a very brittle, flat fracture surface of the Z-pins. This

462 highlights that the pins did not have enough time to deform and simply failed in pure

463 shear, with a much larger contribution to the delamination traction forces and a much

464 shorter bridging zone length.

465 The results highlight how the Z-pinned composites appear to significantly improve

466 the initiation fracture toughness of a composite laminate when loaded at high strain

467 rates $(\dot{\gamma}>10 \mathrm{rad} / \mathrm{s})$. By defining $G_{I I Z_{-} \_ \text {min }}$ as the apparent fracture toughness of a crack

468 with a row of Z-pins directly ahead of it (i.e. no extrinsic Z-pins bridging the crack)

469 tested at quasi-static strain rates (if $G_{I I Z_{-} \min }$ is not available, this can be set to $G_{I I C}$ of

470 the host material), the critical strain energy release rate of a crack behind a row of Z-

471 pins can be defined as the function of shear strain rate $\dot{\gamma}$ :

$$
G_{I I Z}(\dot{\gamma})=G_{I I Z \_ \text {max }} \frac{G_{I I Z \_ \text {min }}-G_{I I Z \_m a x}}{1+\frac{\dot{\gamma}}{m}}
$$

472 Where $m$ is a fitting factor is calculated using a linear least square fit to be 27, Figure

473 17. The initiation $\mathrm{G}_{\text {IIC }}$ for the pinned composite does appear to asymptote towards an

474 upper limit, which can be equated to $G_{I I Z_{-} \text {max }} \approx 3400 \mathrm{~J} / \mathrm{m}^{2}$, the theoretical maximum

475 apparent toughness for a $0.28 \mathrm{~mm}$ diameter, T700/BMI pin inserted in an array of $2 \%$

476 nominal areal density, calculated using single pin experiments [42-44]. 


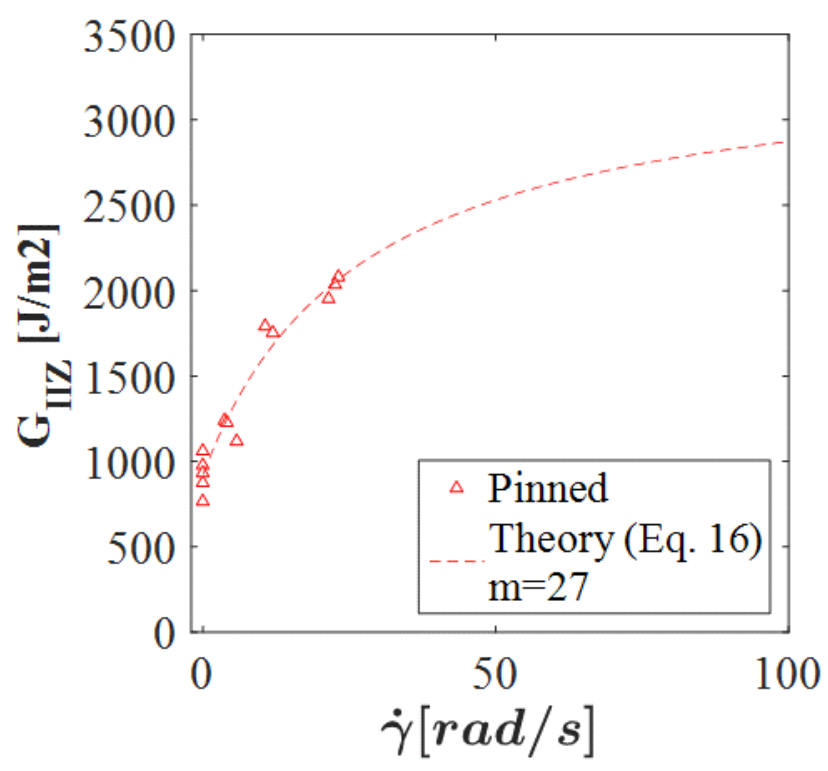

Figure 17 Guz plot against shear strain rate $(\dot{\gamma})$ showing the theoretical fit of equation (16) with $\mathbf{m = 2 7}$

479 The delamination response of unpinned and pinned laminates at higher displacement

480 loading rates is expected to provide the upper plateau for $\mathrm{G}_{\mathrm{IIC}}, \mathrm{G}_{\mathrm{IIZ}}$ and the

481 delamination velocity and would be important to characterize experimentally.

482 However, with increasing loading rates, the influence of kinetic energy on the

483 apparent fracture toughness calculations will become more significant and will have

484 to be fully considered. Furthermore, the delamination response to a high energy soft

485 projectile may produce significantly different failure process and thus may be an

486 interesting area to explore.

\section{Acknowledgements}

488 The authors would like to acknowledge Rolls-Royce plc for their support of this

489 research through the Composites University Technology Centre (UTC) at the

490 University of Bristol, UK. 


\section{References}

493 [1] Kinloch AJ, Shaw SJ, Tod DA, Hunston DL. "Deformation and fracture behaviour of a rubber-toughened epoxy: 1 . Microstructure and fracture studies," Polymer, vol. 24, no. 10, pp. 1341-1354, Oct. 1983.

[2] Shivakumar Gouda PS, Williams JD, Yasaee M, Chatterjee V, Jawali D, Rahatekar SS, Wisnom MR. "Drawdown prepreg coating method using epoxy terminated butadiene nitrile rubber to improve fracture toughness of glass epoxy composites," Journal of Composite Materials, May 2015.

[3] Yasaee M, Bond IP, Trask RS, Greenhalgh ES. "Mode I interfacial toughening through discontinuous interleaves for damage suppression and control," Composites Part A: Applied Science and Manufacturing, vol. 43, no. 1, pp. 198-207, Jan. 2012.

[4] Yasaee M, Bond IP, Trask RS, Greenhalgh ES. "Mode II interfacial toughening through discontinuous interleaves for damage suppression and control," Composites Part A: Applied Science and Manufacturing, vol. 43, no. 1, pp. 121-128, Jan. 2012.

[5] Partridge IK, Yasaee M, Allegri G, Lander JK. "Damage-tolerant composite structures by Z-pinning," in Toughening Mechanisms in Composite Materials, Elsevier, 2015, pp. 161-189.

[6] Yasaee M, Mohamed G, Allegri G, Hallett SR. "Mixed mode delamination resistance of Z-pinned multi-directional composites Part I: Experimental Characterisation," Engineering Fracture Mechanics, 2016.

[7] Lenzi F, Riccio A, Clarke A, Creemers R. "Coupon tests on z-pinned and unpinned composite samples for damage resistant applications," Macromolecular Symposia, vol. 247, pp. 230-237, 2007.

[8] Partridge IK, Cartie DDR. "Delamination resistant laminates by Z-Fiber pinning: Part I manufacture and fracture performance," Composites Part A: Applied Science and Manufacturing, vol. 36, no. 1, pp. 55-64, 2005.

[9] Pegorin F, Pingkarawat K, Mouritz AP. "Comparative study of the mode I and mode II delamination fatigue properties of z-pinned aircraft composites," Materials \& Design, vol. 65, pp. 139-146, Sep. 2014.

[10] Gerlach R, Siviour CR, Wiegand J, Petrinic N. "The Strain Rate Dependent Material Behavior of S-GFRP Extracted from GLARE," Mechanics of Advanced Materials and Structures, vol. 20, no. 7, pp. 505-514, Aug. 2013.

[11] Jacob GC, Starbuck JM, Fellers JF, Simunovic S, Boeman RG. "Fracture toughness in random-chopped fiber-reinforced composites and their strain rate dependence," Journal of Applied Polymer Science, vol. 100, no. 1, pp. 695701, 2006.

[12] Kusaka T, Horikawa N, Masuda M. "Low-velocity impact fracture behaviour of impact-resistant polymer matrix composite laminates under mixed mode loading," Le Journal de Physique IV, vol. 10, no. PR9, p. Pr9-317-Pr9-322, Sep. 2000.

[13] You H, Yum Y-J. "Loading Rate Effect on Mode I Interlaminar Fracture of Carbon/Epoxy Composite," Journal of Reinforced Plastics and Composites, vol. 16, no. 6, pp. 537-549, Apr. 1997. 
[14] Kageyama K, Kimpara I. "Delamination failures in polymer composites," Materials Science and Engineering A, vol. 143, no. 1-2, pp. 167-174, 1991.

[15] Blackman BRK, Dear JP, Kinloch a. J, Macgillivray H, Wang Y, Williams JG, Yayla P. "The failure of fibre composites and adhesively bonded fibre composites under high rates of test - Part I Mode I loading-experimental studies," Journal of Materials Science, vol. 30, pp. 5885-5900, 1995.

[16] Compston P, Jar P-YB, Burchill PJ, Takahashi K. "The effect of matrix toughness and loading rate on the mode-II interlaminar fracture toughness of glass-fibre/vinyl-ester composites," Composites Science and Technology, vol. 61, no. 2, pp. 321-333, 2001.

[17] Smiley a. J, Pipes RB. "Rate sensitivity of mode II interlaminar fracture toughness in graphite/epoxy and graphite/PEEK composite materials," Composites Science and Technology, vol. 29, pp. 1-15, 1987.

[18] Mall S, Law GE, Katouzian M. "Loading Rate Effect on Interlaminar Fracture Toughness of A Thermoplastic Composite," Journal of Composite Materials, vol. 21, no. June 1987, pp. 569-579, 1987.

[19] Maikuma H, Gillespie JW, Wilkins DJ. "Mode II Interlaminar Fracture of the Center Notch Flexural Specimen under Impact Loading," Journal of Composite Materials, vol. 24, no. 2, pp. 124-149, Feb. 1990.

[20] Major Z, Lang RW. "Rate Dependent Fracture Toughness of Plastics," in European Structural Integrity Society, vol. 32, 2003, pp. 187-198.

[21] Barton JM. "Epoxy Resins and Composites I," in Advances in Polymer Science, vol. 72, Berlin, Heidelberg, Berlin, Heidelberg: Springer Berlin Heidelberg, 1985, pp. 111-154.

[22] Cox BN, Gao H, Gross D, Rittel D. "Modern topics and challenges in dynamic fracture," Journal of the Mechanics and Physics of Solids, vol. 53, no. 3, pp. 565-596, 2005.

[23] Rosakis AJ. "Intersonic shear cracks and fault ruptures," Advances in Physics, vol. 51, no. 4, pp. 1189-1257, 2002.

[24] Tsai JL, Guo C, Sun CT. "Dynamic delamination fracture toughness in unidirectional polymeric composites," Composites Science and Technology, vol. 61, no. 1, pp. 87-94, 2001.

[25] Colin de Verdiere M, Skordos AA, Walton AC, May M. "Influence of loading rate on the delamination response of untufted and tufted carbon epoxy noncrimp fabric composites/Mode II," Engineering Fracture Mechanics, vol. 96, pp. 1-10, 2012.

[26] Guo C, Sun CT. "Dynamic Mode-I crack-propagation in a carbon/epoxy composite," Composites Science and Technology, vol. 58, no. 9, pp. 14051410, 1998.

[27] Jiang W, Tjong S, Chu P, Li R. "Interlaminar Fracture Properties of Carbon Fibre/Epoxy Matrix Composites Interleaved with Polyethylene Terephthalate (PET) Films," Polymers and Polymer Composites, vol. 9, no. 2, pp. 141-146, 2001.

[28] Liu H, Yan W, Yu X, Mai Y. "Experimental study on effect of loading rate on mode I delamination of z-pin reinforced laminates," Composites Science and 
Technology, vol. 67, no. 7-8, pp. 1294-1301, Jun. 2007.

[29] Andrew Schlueter, Parab ND, Chen W. "Loading rate effects on mode I delamination of Z-pinned composite laminates," in Dynamic Behavior of Materials, Volume 1, Cham, B. Song, D. Casem, and J. Kimberley, Eds. Cham: Springer International Publishing, 2014.

[30] ASTM-D7905-14. "Standard Test Method for Determination of the Mode II Interlaminar Fracture Toughness of Unidirectional Fiber-Reinforced Polymer Matrix Composites," ASTM International, 2014.

[31] ASTM D790-07. "Standard test methods for flexural properties of unreinforced and reinforced plastics and electrical insulating materials," ASTM International, vol. (2007)e1, 2007.

[32] Hallett SR. "Three-point beam impact tests on T300/914 carbon-fibre composites," Composites Science and Technology, vol. 60, no. 1, pp. 115-124, Jan. 2000.

[33] Gerlach R, Siviour CR, Petrinic N, Wiegand J. "Experimental characterisation and constitutive modelling of RTM-6 resin under impact loading," Polymer, vol. 49, no. 11, pp. 2728-2737, 2008.

[34] Wiegand J, Hornig a., Gerlach R, Neale C, Petrinic N, Hufenbach W. "An Experimental Method for Dynamic Delamination Analysis of Composite Materials by Impact Bending," Mechanics of Advanced Materials and Structures, vol. 22, no. 5, pp. 413-421, 2015.

[35] Weeks CA, Sun CT. "Modeling non-linear rate-dependent behavior in fiberreinforced composites," Composites Science and Technology, vol. 58, no. 3-4, pp. 603-611, Mar. 1998.

[36] de Moura MFSF, de Morais AB. "Equivalent crack based analyses of ENF and ELS tests," Engineering Fracture Mechanics, vol. 75, pp. 2584-2596, 2008.

[37] Wang Y, Williams JG. "Corrections for mode II fracture toughness specimens of composites materials," Composites Science and Technology, vol. 43, no. 3, pp. 251-256, 1992.

[38] Koerber H, Xavier J, Camanho PP. "High strain rate characterisation of unidirectional carbon-epoxy IM7-8552 in transverse compression and in-plane shear using digital image correlation," Mechanics of Materials, vol. 42, no. 11, pp. 1004-1019, 2010.

[39] Pegorin F, Pingkarawat K, Daynes S, Mouritz AP. "Mode II interlaminar fatigue properties of z-pinned carbon fibre reinforced epoxy composites," Composites Part A: Applied Science and Manufacturing, Aug. 2014.

[40] Cartie DDR, Troulis M, Partridge IK. "Delamination of Z-pinned carbon fibre reinforced laminates," Composites Science and Technology, vol. 66, pp. 855861, 2006.

[41] Yasaee M, Mohamed G, Hallett SR. "Multiple delamination interaction in Zpinned composites in Mode II," Experimental Mechanics, 2016.

[42] Yasaee M, Lander J, Allegri G, Hallett S. "Experimental characterisation of mixed mode traction-displacement relationships for a single carbon composite Z-pin," Composites Science and Technology, vol. 94, pp. 123-131, 2014.

[43] Allegri G, Yasaee M, Partridge IK, Hallett SR. "A novel model of 
delamination bridging via Z-pins in composite laminates," International Journal of Solids and Structures, vol. 51, no. 19-20, pp. 3314-3332, Oct. 2014.

[44] Zhang B, Yasaee M, Hallett SR, Allegri G. "Micro-Mechanical Finite Element

630 Analysis of Z-pins under Mixed-Mode Loading," Composites Part A: Applied

631 Science and Manufacturing, 2015.

632 
2017-05-04

Strain rate dependence of mode II delamination resistance in through thickness reinforced laminated composites

\author{
Yasaee, Mehdi
}

Elsevier

Yasaee M, Mohamed G, Pellegrino A, Petrinic N, Hallett SR, Strain rate dependence of mode II delamination resistance in through thickness reinforced laminated composites, International pÿJournal of Impact Engineering, Volume 107, September 2017, Pages 111.

http://dx.doi.org/10.1016/j.jimpeng.2017.05.003

Downloaded from Cranfield Library Services E-Repository 